\title{
Desenvolvimento humano e cultura: integração entre filogênese, ontogênese e contexto sociocultural
}

\author{
Gabriela Dal Forno Martins \\ Universidade Federal do Rio Grande do Sul \\ Mauro Luís Vieira \\ Universidade Federal de Santa Catarina
}

\begin{abstract}
Resumo
O presente artigo tem como objetivo principal apresentar reflexão teórica sobre a integração entre aspectos da história filogenética do ser humano e a história de desenvolvimento ontogenético, considerando o contexto sociocultural onde o indivíduo está inserido. Pressupostos da Psicologia do Desenvolvimento Evolucionista, da Psicologia Transcultural e da Psicologia da Cultura são utilizados como referenciais teóricos. Conceitos como epigênese são apresentados para indicar a relação entre genética e fatores ambientais. Diferentes conceitos de cultura também são expostos e discutidos criticamente. Por fim, relações entre modelos culturais de independência e interdependência com as trajetórias de desenvolvimento são apresentadas e discutidas. Através da análise crítica apresentada, conclui-se que o estudo do desenvolvimento (em suas dimensões em termos de filogênese e ontogênese) mediado pelo contexto sociocultural é consistente e representa um modelo promissor para gerar programas de pesquisas inovadores e originais.
\end{abstract}

Palavras-chave: Psicologia do Desenvolvimento Evolucionista; filogênese; ontogênese; cultura; desenvolvimento humano.

\begin{abstract}
Human development and culture: integration among phylogeny, ontogeny and sociocultural context. The present study aimed to present a theoretical reflection on the integration of aspects of the phylogenetic history of human beings and history of ontogenetic development, considering the socio-cultural context where the individual is inserted. Assumptions of Evolutionary Psychology, Cross-Cultural Psychology and the Psychology of Culture are used as theoretical background. Concepts such as epigenesis are presented to indicate the relationship between genetics and environmental factors. Different concepts of culture are shown and discussed critically. Finally, relations between cultural models of independence and interdependence with the trajectories of development are presented and discussed. Through the critical analysis presented, it is concluded that the study of development (in its dimensions in terms of phylogeny and ontogeny) mediated by the socio-cultural context is consistent and represents a promising model to generate innovative and original research programs.
\end{abstract}

Keywords: Evolutionary Development Psychology; phylogeny; ontogeny; culture; human development.

\section{Psicologia do Desenvolvimento Evolucionista}

A Psicologia Evolucionista tem como objetivo amplo compreender o comportamento humano a partir, principalmente, dos pressupostos da Teoria da Evolução de Darwin, a qual teve grande repercussão na ciência ao introduzir uma nova matriz de entendimento dos fenômenos: o funcionalismo. Segundo Gould (1997), a noção fundamental da evolução se refere à idéia de que os seres vivos mudam com o tempo em virtude de novas pressões ambientais, não se tornando necessariamente superiores, mas melhor adaptados às condições ambientais.

Nesse sentido, quais são as contribuições da Psicologia
Evolucionista para o entendimento do processo de desenvolvimento humano? Seidl-de-Moura (2005) discutindo a respeito do desenvolvimento na ontogênese a partir da Psicologia Evolucionista, afirma que o foco desta abordagem em geral é na mente adulta, a qual processa informação por meio de módulos especializados. Dessa forma, Barkow, Cosmides e Tooby (1992), na ocasião em que lançam as principais idéias da Psicologia Evolucionista, não atribuem um lugar importante para a ontogênese, ou seja, para o processo de construção ao longo do curso de vida. Uma explicação possível para isso seria a de que a ênfase na fase adulta tenha relação com a importância atribuída ao fenômeno da reprodução, conceito chave na teoria 
da evolução de Darwin (Bjorklund \& Pellegrini, 2000).

Outra explicação para o foco na mente adulta pode ser encontrada nas idéias de Tooby e Cosmides (1992), no capítulo "The Psychological Foundations of Culture", no qual apresentam as idéias evolucionistas partindo da crítica ao modelo padrão das ciências sociais (Standard Social Sciences Model/ SSSM). Como esse modelo destaca, prioritariamente, o papel da ontogênese na explicação do desenvolvimento humano, hipotetiza-se que a negligência da ontogênese pelos autores da Psicologia Evolucionista deva-se também a uma reação a esse modelo. Segundo Tooby e Cosmides (1992), o SSSM entende o funcionamento humano com base em alguns pressupostos: 1) os bebês nascem com o mesmo aparato biológico, portanto, algo tão constante não seria capaz de explicar a variação verificada no comportamento dos adultos; 2) como os bebês não possuem toda competência cognitiva e social dos adultos, sua estrutura rudimentar precisa de uma fonte externa para desenvolver-se, algo fora deles; 3) a fonte de que o bebê precisa está presente no mundo social na forma de comportamentos e representações dos membros dos grupos, a cultura. Assim, a organização mental é categorizada em: inata (o que vem com o bebê, é visível, geneticamente programada, biológica), e social (cultural, aprendida ou adquirida no ambiente).

Os autores que trabalham especificamente com a Psicologia do Desenvolvimento Evolucionista - PDE (Bjorklund \& Pellegrini, 2000; Bjorklund \& Smith, 2003; Charlesworth, 1992; Keller, 2002; Seidl-de-Moura 2005), pensam que é possível atribuir um papel relevante para a ontogênese e, ao mesmo tempo, adotar uma perspectiva evolucionista. Parte-se da ideia de que o comportamento adulto, principalmente a possibilidade de reprodução, depende de como os indivíduos desenvolveramse até chegar a maturidade sexual, sendo isso especialmente importante na espécie humana, que passa por um longo período de imaturidade e dependência (Bjorklund \& Pellegrini, 2000).

A PDE é uma área de intersecção entre a Psicologia do Desenvolvimento e a Psicologia Evolucionista. Assim, existem alguns pressupostos que são compartilhados atualmente pelos autores da Psicologia do Desenvolvimento. Por exemplo, entendemos que existe certo consenso a respeito da necessidade de olhar para o desenvolvimento sob uma ótica pluralista e interacionista. Aspesi, Dessen e Chagas (2005) afirmam que frente a muitas críticas relacionadas a dicotomias e determinismos, pensa-se hoje ser mais adequado trabalhar com naturezas teóricas diversas, bem como considerar o desenvolvimento como um fenômeno não linear, como um processo de mudança progressiva que ocorre com base nas interações estabelecidas dentro de um contexto, sendo que tais interações envolvem fatores biológicos, psicológicos, sociais e culturais.

Geary (2006), aproximando-se deste conceito, define, de modo bastante pertinente e elucidativo, que a Psicologia do Desenvolvimento trata do estudo dos traços e fenótipos ${ }^{1}$ comportamentais (por exemplo, exploração de objetos), sociais (ex.: brincadeira), cognitivos (ex.: linguagem) e físicos (ex.: puberdade), e dos mecanismos que influenciam as mudanças nesses fenótipos ao longo do curso de vida. Além disso, afirma que esses mecanismos envolvem relações recíprocas entre a expressão genética e os ambientes interno e externo do indivíduo.
Essa visão interacionista, hoje, é dificilmente questionada pelos pesquisadores da área. No entanto, esforços são necessários para explicar "como" os genes e o ambiente interagem para produzir um fenótipo específico.

É nesse sentido que a PDE tem procurado contribuir, tanto com a Psicologia do Desenvolvimento como um todo, quanto com a Psicologia Evolucionista especificamente. Dessa forma, o principal objetivo da PDE é fornecer um modelo explicativo sobre como os mecanismos de desenvolvimento psicológicos expressam-se nos fenótipos dos indivíduos, enfatizando o papel da seleção natural, não somente na fase adulta, mas em todas as fases do ciclo de vida (Grotuss, Bjorklund, \& Csinady, 2007).

O conceito de epigênese vem sendo utilizado por grande parte dos autores da PDE de modo bastante apropriado (Bjorklund \& Pellegrini, 2000; Geary \& Bjorklund, 2000; Grotuss et al., 2007; Keller, 2002) para explicar a relação entre a genética e os fatores ambientais. Esse conceito é importante e traz contribuições relevantes para o avanço da área, pois diz respeito a um processo que envolve a ação de genes, proteínas, neurônios e do ambiente (incluindo a cultura) na emergência de novas estruturas e funções durante o curso de desenvolvimento. Segundo Geary e Bjorklund (2000), o processo epigenético gera tanto características fenotípicas comuns aos membros da espécie humana como variações no comportamento adaptadas às ecologias locais. Nesse sentido, segundo Keller (2002) o desenvolvimento seria resultado da interação entre a herança biológica e aspectos culturais específicos, rejeitando o determinismo biológico, e enfatizando relações transacionais entre o organismo e o ambiente. Assim, podemos afirmar que a relação indivíduo-ambiente é bidirecional, pois os indivíduos modificam o ambiente (escolhendo e construindo seus nichos) e, ao mesmo tempo, o ambiente modifica o indivíduo (alterando os comportamentos conforme as demandas ecológicas específicas) (Bjorklund \& Pellegrini, 2000).

Também é importante destacar que o processo epigenético, do ponto de vista da emergência de novas estruturas e funções durante o curso de desenvolvimento, é relacionado, na Psicologia, ao conceito de aprendizagem. No entanto, tendo como base a epigênese, torna-se necessário utilizar um conceito de aprendizagem que vá além daquele utilizado no modelo padrão das ciências sociais (SSSM) (Tooby \& Cosmides, 1992). Segundo esses autores, embora a idéia de tábula rasa tenha sido deixada de lado mesmo no modelo padrão das ciências sociais, isso não modificou o pressuposto central deste modelo de que a natureza humana seria somente o material moldado e transformado pelo social. Assim, a aprendizagem, nesta perspectiva, seria o meio pelo qual a criança torna-se adulto, socializa-se, sendo o indivíduo passivo diante da cultura, um produto da mesma.

Tooby e Cosmides (1992) afirmam que um dos principais problemas do SSSM diz respeito à utilização de um processo, a aprendizagem, para explicar a emergência de novos comportamentos, sem considerar que a própria aprendizagem necessita ser explicada. Segundo eles, quando se discute a cultura, nada além da "caixa preta" da aprendizagem é considerado. Portanto, os autores afirmam de modo contundente que o conceito de aprendizagem é suficientemente forte para 
explicar qualquer comportamento adquirido, e deve ser também suficiente para explicar qualquer aspecto da organização humana que varia de indivíduo para indivíduo e de grupo para grupo.

Uma proposta diferenciada, e da qual estendemos que permite superar a dicotomia inato-aprendido ou biológicocultural, é fornecida pela perspectiva evolucionista. Inicialmente, Tooby e Cosmides (1992) propuseram que os mecanismos de desenvolvimento psicológicos possuem mecanismos sensíveis às variações ambientais, ao mesmo tempo em que possuem regras e procedimentos especializados. Os autores anteriormente citados também acrescentam que os mecanismos psicológicos permitem a estruturação da vida social humana e a transmissão cultural através das gerações.

Fica evidente nesse primeiro conceito que, para a Psicologia Evolucionista, a aprendizagem não é um processo aleatório. Essa idéia é compartilhada e desenvolvida pelos autores da PDE. Keller (2002) afirma que a primeira tarefa do desenvolvimento da criança consiste em desenvolver relações de aprendizagem com os cuidadores primários, e conceitua a aprendizagem como:

um processo de desenvolvimento, guiado por regras epigenéticas que direcionam a atenção dos bebês para seus parceiros sociais e permitem uma aprendizagem facilitada dos parâmetros que definem as relações dentro de um contexto específico e, consequentemente, o desenvolvimento de um self contextual (p. 217).

Para explicar as regras epigenéticas, Keller (2002) utiliza dois conceitos cunhados por Mayr (1988): os programas fixos e os programas abertos. Grotuss et al. (2007) utilizam conceitos semelhantes: a epigênese pré-determinada e a epigênese probabilística. Fazendo uma relação entre esses conceitos, podese afirmar que a epigênese pré-determinada seria guiada pelos programas fixos, os quais, segundo Keller (2002), são codificados invariavelmente no DNA, ou seja, controlam principalmente mudanças macro-morfológicas que precisam do ambiente para se expressar, mas este não exerce efeitos diferenciais. Grotuss et al. (2007) acrescentam que a epigênese pré-determinada é responsável pelos efeitos unidirecionais, em que a atividade genética conduz à maturação estrutural, a qual, por sua vez, conduz ao funcionamento, à atividade ou à experiência.

A epigênese probabilística, por outro lado, seria guiada pelos programas abertos, estes sim preparados para adquirir informação através da aprendizagem. Tanto para Keller (2002), quanto para Grotuss et al. (2007), são estes programas que possibilitam os efeitos diferenciais da influência do ambiente, sendo esta influência possível em função das relações bidirecionais entre estrutura e funcionamento. Assim, segundo os últimos autores, a atividade genética afetaria e seria afetada pela maturação estrutural, e esta afetaria e seria afetada pela experiência.

Resumidamente, podemos afirmar que a PDE considera que o desenvolvimento emerge de relações complexas entre o indivíduo e o ambiente que o circunda. Conforme mencionado anteriormente, essa visão interacionista é amplamente aceita, mas, muitas vezes não se explora adequadamente como a interação ocorre e qual o papel dos diferentes determinantes. Em relação a isso, a PDE tem procurado contribuir para que o papel do indivíduo seja mais bem explorado, utilizando-se da teoria evolucionista para demonstrar como os mecanismos de desenvolvimento psicológicos atuam na emergência de comportamentos específicos. Como um próximo passo, alguns autores como Keller (2007), Seidl-de-Moura (2005) e Tooby e Cosmides (1992) têm procurado cunhar novos conceitos de cultura ou articular os conceitos já existentes a esse "novo indivíduo".

\section{Diferentes definições sobre cultura}

O crescente interesse em compreender os aspectos biológicos do desenvolvimento humano, vindo principalmente da Psicologia Evolucionista e das Neurociências, vem impulsionando, ao mesmo tempo, o interesse pelo papel da cultura. No entanto, essa tarefa não é fácil e precisa de mais investimento por parte dos pesquisadores para que possa ser bem sucedida. Conforme Miller (1999, 2002), os esforços para integrar os aspectos biológicos à cultura ainda são limitados, tendo em vista a negligência das produções recentes das áreas que trabalham tradicionalmente com a cultura na Psicologia, como por exemplo, a Psicologia da Cultura. Como existem divergências nas explicações sobre a relação entre biologia e cultura, nessa seção serão apresentadas brevemente diferentes concepções de cultura e suas articulações, de modo a aproximar-se de uma concepção que possa aprimorar a compreensão do desenvolvimento proposta pela PDE. Entendemos que as diferentes perspectivas podem trazer contribuições relevantes para o avanço na área, mas a articulação da biologia com a cultura que leva em consideração aspectos do desenvolvimento individual e social precisa ser considerada para que tenhamos uma visão mais holística do fenômeno.

Tooby e Cosmides (1992), ao realizar a crítica ao modelo padrão das ciências sociais, criticam também a concepção de cultura utilizada para explicar as diferenças intergrupais e similaridades intragrupais. Essa concepção entende a cultura como uma entidade externa aos indivíduos, um conjunto de comportamentos, crenças, sistemas ideológicos amplamente distribuídos em um determinado grupo, que são mantidos e transmitidos pelo mesmo. As diferenças entre os grupos são explicadas através da existência de limites, de "correntes" que separam uma cultura da outra. Assim, os determinantes da cultura estariam no nível grupal e seriam independentes do nível individual, restando ao indivíduo o papel de "aprender" a cultura e assim replicá-la de geração em geração. Como conseqüência disso, a cultura não seria nem na forma, nem no conteúdo, afetada ou determinada pela biologia humana, pela natureza humana ou qualquer design psicológico herdado.

Quando os autores citados acima descrevem o modelo padrão das ciências sociais, tratam esse grupo como um conjunto homogêneo, mas não distinguem autores ou abordagens específicas. Na Psicologia, existem algumas vertentes que trabalham especificamente com a cultura, e que em alguns aspectos aproximam-se desse modelo, e em outros se distanciam do mesmo. Ribas e Seidl-de-Moura (2006), por exemplo, adotam a terminologia Sociocultural para se referir a uma ampla vertente na Psicologia, que engloba autores da Psicologia da Cultura e da Psicologia Transcultural. No presente estudo, serão analisadas as concepções de dois autores da Psicologia da Cultura (Cole, 2002; Miller, 1999, 2002) e suas possibilidades de intersecção com 
autores da Psicologia Evolucionista (Tooby \& Cosmides 1992).

Miller (1999) apresenta argumentos para sustentar a idéia de que a cultura precisa ser vista como implicada diretamente nos processos psicológicos básicos, ou seja, que ela é necessária para a emergência desses processos. Para tanto, parte de um conceito de cultura que focaliza os aspectos simbólicos e intersubjetivos, e critica as visões ecológicas da cultura, ou seja, as que consideram somente a experiência objetiva em termos de características sociodemográficas, recursos, aspectos geográficos, etc. Para Miller (2002), pensar a cultura como representando um ambiente simbólico, ou seja, como sistemas de significado compartilhados, não elimina a importância de se considerar os aspectos ecológicos, mas sugere que eles são insuficientes para explicar a influência do contexto no desenvolvimento humano.

Apesar de Miller (1999) afirmar que essa abordagem da cultura não nega a experiência individual dos processos psicológicos, parece que sua principal unidade de análise são os significados compartilhados e que a cultura seria algo exterior ao indivíduo. Com relação a esse aspecto, pode-se dizer que a concepção de Miller aproxima-se do modelo padrão das ciências sociais. Por outro lado, o autor contribui quando distingue as concepções ecológicas da cultura da concepção simbólica, enfatizando que existem também aspectos que influenciam o comportamento num nível implícito.

Um último ponto importante com relação às idéias deste autor refere-se à maneira com que ele concebe a relação entre aspectos universais do comportamento e o papel da cultura. Miller (1999) afirma que é comum na Psicologia entender-se os padrões universais do desenvolvimento como não sendo afetados pela cultura, como se somente as variações do comportamento pudessem ser fruto das influências culturais. Como o autor defende a ideia de que os fatores contextuais, incluindo a cultura, são necessários para a emergência dos processos psicológicos, conclui que também a experiência sociocultural é universal. Essa visão aproxima-se da noção do ser humano como uma espécie biologicamente cultural (Bussab \& Ribeiro, 1998), e neste aspecto distancia-se do modelo padrão das ciências sociais, pois coloca a cultura como sendo produtora do homem, e ao mesmo tempo produto de sua capacidade de representar e dar significados para a realidade.

Concordamos com Seidl-de-Moura (2005) quando ela afirma de modo incisivo que, para articular o papel da cultura com a perspectiva evolucionista, é necessário considerar o plano individual e demonstrar como o indivíduo está implicado na construção da cultura. Cole (2002), outro autor da Psicologia da Cultura, parece caminhar mais nesse sentido, uma vez que coloca a cultura como sendo também produto da história filogenética do homem. Assim, discute o quanto o uso mais complexo de instrumentos, cérebros maiores e mais complexos e diferenças na organização social contribuíram para a emergência da cultura (Seidl-de-Moura, 2005).

Nesse sentido, é bastante apropriada a definição de cultura proposta por Cole (2002). O autor define cultura como sendo um conjunto estruturado de artefatos (modelos culturais, scripts) que é, ao mesmo tempo, material e ideal (está na mente do homem e simultaneamente materializado no seu ambiente). Os artefatos são "aspectos do mundo material que foram modificados através da história de sua incorporação em ações humanas dirigidas a metas" (Cole, 2002, p. 306), e isso somente foi possível através da evolução humana. Verifica-se que na sua concepção fica mais evidente o papel ativo do indivíduo, pois foram e são as atividades dos próprios homens, materializadas, que possibilitam a construção de artefatos ideais, de idéias, crenças e significados compartilhados.

Além disso, Cole (2002) dedica-se a explicar como as histórias filogenética (história da espécie humana) e sociocultural (desenvolvimento de gerações em uma sociedade) imbricamse na ontogênese. De maneira geral, o autor afirma que, no nascimento, o bebê traz consigo uma organização biológica que é produto da história filogenética. No entanto, até mesmo antes de nascer já está inserido num ambiente sociocultural, que o modifica e é modificado por ele. Dessa forma, "no nascimento, o desenvolvimento se torna um processo co-construtivo em que o ambiente e o bebê são agentes ativos" (Cole, 2002, p. 306). Afirma, ainda, que essas transações entre o bebê e o ambiente em geral são mediadas pela cultura.

Em nosso entendimento, a concepção de cultura que contemple de maneira mais aprofundada o papel do indivíduo e dos mecanismos de desenvolvimento psicológicos seja aquela proposta por Tooby e Cosmides (1992). Para esses autores, a cultura deve ser explicada em três aspectos distintos. O primeiro deles traz como pressuposto a idéia de que a própria arquitetura mental universal é a principal responsável pelas semelhanças entre as pessoas de um mesmo grupo e diferenças entre grupos distintos. Para tanto, utilizam o conceito de cultura evocada, no sentido de que as semelhanças e diferenças são geradas por mecanismos psicológicos funcionalmente organizados, de conteúdo específico e ativados por circunstâncias locais. As condições ecológicas compartilhadas pelos membros de uma população local podem explicar numerosas similaridades em aspectos como padrões de criação de filhos, hábitos de alimentação, tecnologias de trabalho, entre outros. Condições geográficas, como relevo, vegetação, altitude e clima influenciam fortemente vários aspectos do ambiente, como fontes de recursos, vegetais e animais, presas e predadores, entre outros aspectos, aos quais os grupos humanos devem responder com adaptações locais.

O segundo componente da cultura para Tooby e Cosmides (1992) trata da cultura epidemiológica, cujo papel complementa a cultura evocada na explicação das similaridades e diferenças. A cultura epidemiológica refere-se a representações compartilhadas por uma população, que são construídas por mecanismos inferenciais do observador, sendo esses mecanismos similares entre todos os membros da espécie. A facilidade de disseminação dessas representações é afetada por mecanismos psicológicos específicos. Independentemente da acepção do conceito de cultura que se leve em conta, não se pode falar em transmissão de cultura e, sim, em reconstrução. Essa proposição enfatiza a primazia do indivíduo, dos mecanismos psicológicos do aprendiz que, por meio da observação e da inferência, reconstrói mentalmente as representações sociais existentes (nas mentes dos outros). Isso significa que vários aspectos da cultura são "herdados" de uma geração para outra, sem outra razão que não o fato de que eles são os modelos disponíveis. 
O terceiro e último aspecto denomina-se metacultura, um conceito que possibilita a explicação das semelhanças existentes entre os indivíduos, que são geradas por mecanismos psicológicos organizados funcionalmente, compartilhados por todos os indivíduos da espécie e responsáveis pelas respostas similares às regularidades do mundo físico e social, em todas as culturas. Como exemplo pode-se citar o pesar diante de uma perda e as crenças em que os outros possuem mentes (teoria da mente). Essas regularidades transculturais existem apenas em função das semelhanças entre os organismos que compartilham suas culturas.

Podemos perceber distinções claras principalmente no que diz respeito à influência das características da espécie na construção da cultura. Para a Psicologia da Cultura a ênfase está centrada na interação social entre indivíduos em um determinado momento histórico. A cultura não está "fora" dos indivíduos, ela faz parte da "realidade intersubjetiva" destes e é uma condição inerente para a constituição do sujeito (Ribas \& Seidl-deMoura, 2006). Na perspectiva evolucionista, cultura é um dos mecanismos que foi selecionado ao longo da evolução. Sendo assim, além de conhecer o momento presente, é importante, também, considerar aspectos filogenéticos do ser humano. Durante nossa história enquanto espécie, mecanismos neurais e psicológicos foram selecionados e permitiram aos seres humanos produzir cultura, ajudando na adaptação aos diferentes meios em que viviam (Tooby \& Cosmides, 1992).

Nesse sentido, os autores evolucionistas incluem na sua concepção de cultura tanto os aspectos ecológicos do contexto (cultura evocada), quanto os simbólicos (cultura epidemiológica). Enquanto, principalmente em Miller (1999, 2002), os aspectos simbólicos pareciam existir em nível grupal, independente dos indivíduos, para Tooby e Cosmides (1992) as representações compartilhadas surgem da reconstrução mental das representações sociais existentes (na mente dos outros), e assim são transmitidas. Com essa concepção, os autores evolucionistas fornecem argumentos para a idéia do homem como biologicamente cultural, já que a chave para a compreensão da natureza humana estaria na cultura e a chave para a compreensão da cultura estaria na natureza humana (Bussab \& Ribeiro, 1998). Reforçando essa idéia, Ridley (2004) afirma que é mais promissor e heurístico entender como a natureza se manifesta via cultura e não buscar saber o que é da "natureza" e o que é da "cultura" na manifestação do comportamento.

Pensar dessa forma, não invalida a idéia defendida pelos autores da Psicologia da Cultura de que a cultura seria uma terceira força de influência no desenvolvimento. No entanto, não a coloca como uma instância à parte, mas sim, estritamente relacionada ao indivíduo e aos aspectos ecológicos. Portanto, partimos do pressuposto neste ensaio de que, além de se admitir que a concepção de cultura de Tooby e Cosmides (1992) seja aquela mais compatível com os pressupostos da PDE, incluemse também as contribuições de Miller (1999, 2002) e Cole (2002) referentes ao papel indispensável da cultura no estudo do desenvolvimento humano e na consideração não somente dos aspectos ecológicos, mas também dos sistemas de crenças compartilhados que influenciam o comportamento de forma implícita.

\section{Modelos culturais e trajetórias de desenvolvimento}

Alguns autores têm proposto que as trajetórias de desenvolvimento universais podem ser estudadas na sua relação com diferentes modelos culturais, que incluem tanto sistemas de crenças, quanto características ecológicas diferenciadas (Keller \& Greenfield, 2000). Dois principais modelos são explorados pelos autores, o modelo independente e o modelo interdependente, os quais têm origem nos conceitos de individualismo e coletivismo (I-C) já tradicionalmente estudados na Psicologia Transcultural.

Van de Vijver e Leung (2000) destacam que, dentre os estudos recentes publicados em periódicos específicos da Psicologia Transcultural, os que tiveram mais crescimento foram aqueles relacionados à Psicologia do self e aos modelos culturais individualistas e coletivistas. Como principais representantes desses estudos, os autores citam Kagitcibasi e Triandis. Esse último autor é referência nos estudos envolvendo as dimensões individualismo e coletivismo, e trabalha na descrição desses modelos principalmente em nível cultural (Triandis, Bontempo, Villareal, Asai, \& Lucca, 1988). Por outro lado, a primeira autora dedica-se mais amplamente ao nível individual dessas dimensões, fazendo a interface entre a cultura e o self através do processo de socialização (Kagitcibasi, 2005).

Triandis et al. (1988) afirmam que, através da perspectiva sociológica, as dimensões individualista e coletivista derivam da concepção de que as culturas diferem no grau de ênfase na cooperação e na competição. Do ponto de vista psicológico, essas diferenças se refletem em dimensões da personalidade que os autores denominam alocentrismo e idiocentrismo. $\mathrm{O}$ alocentrismo estaria relacionado a uma valorização prioritária do grupo social e conseqüentemente a maiores índices de suporte social; já no idiocentrismo, a ênfase estaria na realização pessoal. Embora esses autores façam a distinção entre as dimensões culturais e psicológicas do individualismo e coletivismo, dedicam-se a uma descrição mais ampla desses modelos.

As interações entre os componentes de um mesmo grupo, nas culturas coletivistas, são caracterizadas por alta cooperação e interdependência, mas o mesmo não acontece em relação a pessoas de fora do grupo (Triandis et al., 1988). Há, ainda, uma maior ênfase na pessoa do que na tarefa, assim, por exemplo, quando se está atrasado para o trabalho e encontra um amigo no caminho, é mais importante parar para cumprimentá-lo e conversar com ele do que fingir que não o viu ou pedir desculpas e seguir. Por fim, uma última característica importante apontada pelos autores relaciona-se a uma maior utilização, nessas culturas, de mecanismos de controle social como a vergonha e as crenças religiosas.

A cultura individualista, por sua vez, caracteriza-se pela presença de um número maior de grupos dos quais o indivíduo participa (ex.: família, colegas de trabalho, colegas da escola, grupo de esporte). No entanto, mais facilmente as pessoas deixam de participar dos grupos que lhes são inconvenientes e formam novos grupos. Como resultado disso, as demandas feitas ao indivíduo pelo grupo são pontuais e segmentadas, num certo momento do tempo e de conteúdo específico. Assim, 
as interações entre os componentes de um grupo tendem a ser independentes e distantes, podendo o indivíduo fazer as coisas à sua maneira e deixar o grupo (Triandis et al., 1988).

Após a década de 1980, “a década do I-C" segundo Kagitcibasi (2007), essas dimensões passaram a ser alvo de diversas críticas. A principal delas trata do caráter simplista e reducionista desse paradigma cultural, cujos conceitos parecem ser demasiadamente dicotômicos (Greenfield, Keller, Fuligni, \& Maynard, 2003). Essa crítica, todavia, tem como base principalmente os estudos transculturais que utilizavam escalas para comparar amostras nacionais (geralmente universitários) e fazer inferências culturais, cujos resultados são enviesados mais por problemas nas medidas utilizadas do que nos aspectos conceituais.

Kagitcibasi (2007) afirma que essa aparente dicotomização surgiu como uma reação aos trabalhos da psicologia americana, que tradicionalmente enfatizam a autonomia (independência) como um aspecto essencial no desenvolvimento saudável do indivíduo. Dessa forma, num primeiro momento, predominaram visões polarizadas das dimensões I-C, mas, atualmente, elas tendem a ser vistas como dois modelos prototípicos que variam de diversas formas e graus entre as culturas e, inclusive, podem coexistir numa mesma cultura (Greenfield et al., 2003; Kagitcibasi, 2005).

Tendo como base as dimensões I-C, Kagitcibasi (2005) construiu um modelo que relaciona a cultura mais ampla e o self individual através do processo de socialização. Para a compreensão desse modelo, é preciso primeiramente distinguir o que ela denominou I-C normativo e I-C relacional. O primeiro é mais utilizado nas pesquisas transculturais da Psicologia Social e reflete os valores, convenções e regras sociais, os quais indicam que o indivíduo "deveria" (grifo dos autores) subordinar-se aos interesses do grupo (coletivismo) ou não (individualismo). Essa dimensão refere-se àquela descrita anteriormente com base em Triandis et al. (1988). Por outro lado, o I-C relacional foca as relações self-outros, podendo ser de natureza independente (individualismo) ou interdependente (coletivismo), e não está necessariamente relacionado ao I-C normativo.

É na dimensão relacional que Kagitcibasi (2005) baseia-se para construir seu modelo. A autora afirma que a independência ou autonomia é muitas vezes vista como sinônimo de distância interpessoal, separação e, em resposta a isso, novamente divide a dimensão relacional do I-C em outras duas dimensões. Uma delas trata da própria distância interpessoal, que diz respeito ao grau de conexão com os outros (separated self e relational self). A outra é denominada agência e define-se pelo grau de autonomia no funcionamento do indivíduo (autonomia - indivíduo sujeito às próprias leis, heteronomia - indivíduo sujeito às leis dos outros).

Kagitcibasi (2005) demonstra como determinado self emerge em determinado contexto e, nesse sentido, aponta para a necessidade de examinar a relação entre sociedade-famíliaprocesso de socialização. Três diferentes tipos de self são derivados de três tipos de famílias:

1) Família tradicional caracterizada pela interdependência global (distância interpessoal e agência): prevalente em sociedades tradicionalmente rurais, em que a interdependência intergeracional é um requisito para a vida familiar. A criança tem o papel de contribuir ao longo de sua vida para o bem-estar da família, inclusive fornecendo cuidados aos pais durante a velhice. Além disso, em alguns contextos, possui um valor econômico/utilitário para a família, já que pode ajudar no seu sustento. Dessa forma, a alta fertilidade também é característica dessas famílias. Quanto às práticas de cuidado, é valorizada a obediência da criança como uma forma de garantir sua lealdade.

2) Modelo individualista de família baseado na independência: prevalente, de forma ideal, nas famílias nucleares de classe-média ocidentais. A independência intergeracional é valorizada e as práticas de cuidado priorizam o desenvolvimento da autoconfiança e da autonomia na criança. Essas características são vistas como requisitos para um desenvolvimento saudável.

3) Famílias resultantes de uma síntese entre as duas anteriores, envolvendo independência do ponto de vista do funcionamento e interdependência do ponto de vista da distância interpessoal: prevalente em contextos tradicionalmente interdependentes, mas que passaram por um processo de desenvolvimento econômico. Nessas famílias, o envolvimento da criança do ponto de vista da obediência e do utilitarismo não é mais necessário e valorizado. Por outro lado, o aspecto emocional da proximidade interpessoal permanece desejado. Assim, as práticas de cuidado continuam priorizando o controle, já que a separação não é um objetivo, mas dão espaço para que a criança desenvolva autonomia do ponto de vista do funcionamento.

Uma decorrência desses modelos é saber como eles se manifestam na prática quando se analisam contextos específicos. Por exemplo, estudos têm mostrado que o predomínio das dimensões de autonomia e separação tem caracterizado sociedades urbanas pós-industriais e com alto nível de escolaridade (Keller, 2007). Nesse caso, o cuidado físico é caracterizado por períodos curtos de amamentação, pouco contato entre mãe-bebê e a ênfase nos cuidados profissionais às crianças (babás, creches, etc.). Também inclui o predomínio dos sistemas de estimulação face-a-face entre adulto e bebês e estimulação destes através de objetos (Keller, 2002).

No outro pólo está o modelo de interdependência em que valores, metas, crenças e práticas parentais estão relacionadas às prioridades do grupo, focalização dos papéis sociais, deveres e obrigações. Essas características estão presentes principalmente em ambientes rurais baseados na economia de subsistência (Keller, 2007).

Por fim, no modelo autônomo-relacional, que enfatiza o self como autônomo quanto à ação e relacional quanto à proximidade interpessoal, é mais característico de famílias de classe média, urbana e escolarizada em sociedades tradicionalmente interdependentes (Kagitcibasi, 2005). Neste modelo tem sido verificado um predomínio de práticas proximais em relação às distais, mas uma menor valorização das práticas proximais quando comparada a contextos interdependentes (Keller, Borke, Yovsi, Lohaus, \& Jensen, 2005).

Analisar os diferentes contextos de desenvolvimento a partir dos modelos expostos é uma forma de compreender como tarefas de desenvolvimento universais (os cuidados parentais, por exemplo) são solucionadas de formas específicas diante de condições culturais e ecológicas também específicas. Concordamos com Aspesi et al. (2005) quando afirmam que 
esse pode ser um caminho promissor no que se refere ao estudo do desenvolvimento, o qual necessita atualmente ser pensado a partir do curso de vida em sua totalidade, da interação entre componentes genéticos e adquiridos na determinação do comportamento e do indivíduo como um sistema biológico, psicológico, social, inserido em um contexto sociocultural.

\section{Considerações Finais}

Procuramos apresentar ao longo desse estudo teórico uma proposta de como é possível integrar aspectos da história filogenética do ser humano e da sua história de desenvolvimento ontogenético, considerando o contexto sociocultural onde o indivíduo está inserido.

Concordamos com Seidl-de-Moura (2005) quando ela defende um modelo de integração em termos de: 1) uma orientação nem universalista, nem relativista radical, focalizando tanto as variações quanto as semelhanças entre os indivíduos de uma comunidade e entre comunidades; 2) a busca pela compreensão da gênese dos fenômenos psicológicos, dos processos de desenvolvimento, guiada pela análise inseparável dos aspectos individuais e sociais e do desenvolvimento no contexto sociocultural; 3) o desenvolvimento visto sob diferentes níveis de análise: microgenético, ontogenético, sociocultural e filogenético; 4) noção de atividade ou evento como unidade de análise, ou seja, a atividade que os sujeitos realizam no mundo mediado por um significado em um determinado contexto social e cultural; e 5) a pluralidade metodológica e a compreensão de que as próprias questões e métodos de compreensão dos processos psicológicos são também situados cultural e historicamente.

Além do que foi exposto nesse trabalho teórico, é importante também destacar a necessidade investigar de que forma os sistemas de crenças compartilhados influenciam no desenvolvimento infantil. Entre a prerrogativa filogenética que nos coloca a tarefa de cuidar dos recém-nascidos e o comportamento destes, existe o contexto cultural que é mediado pelos pais e mães e/ou cuidadores primários. $\mathrm{O}$ estudo dos sistemas de crenças compartilhadas também deve ser investigado e considerado para futuras análises do desenvolvimento humano. Embora os costumes de cuidados sejam realizados de forma espontânea, geralmente são acompanhados por crenças específicas que lhes confere significados.

Como esse ensaio é teórico, embora embasado em referências de pesquisas empíricas, pode-se questionar a sua validade no sentido de sustentar programas de pesquisas que sejam inovadores e originais. Uma autora que vem conseguindo desenvolver linha sistemática e consistente de pesquisas na área é a professora Dra. Heidi Keller, da Universidade de Osnabruck, Alemanha. Merecem destaque suas pesquisas transculturais, procurando investigar aspectos comuns e específicos das tarefas de desenvolvimento, como por exemplo, o desenvolvimento do self e que está intimamente relacionado com o processo de socialização no âmbito familiar, em suas diferentes configurações. Embora o objetivo dos adultos seja a sobrevivência das crianças e o seu pleno desenvolvimento, a forma como esse processo acontece vai depender do ambiente físico e social. Especificamente nesse último caso, crenças, valores e idéias que as pessoas têm sobre como devem ser as crianças e como devem ser cuidadas, são decisivos para se compreender o desenvolvimento infantil.

Heidi Keller, em parceria com pesquisadores de diferentes instituições ao redor do mundo, escreve artigo sobre estilos parentais (mais próximos - contato corporal e estimulação corporal - ou mais distantes - contato face-a-face estimulação por objetos), comparando nove culturas diferentes, umas mais urbanas e industrializadas e outras localizadas em contextos mais rurais (Keller et al., 2009). Especificamente no Brasil, pesquisas realizadas em várias regiões do país e em distintos contextos também têm mostrado diferenciações nas crenças, valores e práticas de criação de filhos em função do contexto onde as famílias vivem e das condições sociodemográfica (Seidlde-Moura et al., 2008; Vieira et al., 2010).

Com base nas evidências apresentadas podemos constatar especificidades nas estratégias utilizadas pelas famílias e que combinam estilos proximais e distais, além de serem influenciadas por variáveis sociodemográficas. Nesse sentido, conclui-se que existem tarefas de desenvolvimento comuns aos seres humanos e que são solucionadas de diferentes maneiras, dependo do contexto sociocultural, conforme proposta apresentada e defendida pelos autores no presente artigo.

\section{Referências}

Aspesi, C. C., Dessen, M. A., \& Chagas, J. F. (2005). A ciência do desenvolvimento humano: uma perspectiva interdisciplinar. In M. A. Dessen \& A. L. Costa, Jr. (Orgs.), A ciência do desenvolvimento humano: tendências atuais e perspectivas futuras (pp. 19-36). Porto Alegre: Artmed.

Barkow, J., Cosmides, L., \& Tooby, J. (1992). The adapted mind: evolutionary psychology and the generation of culture. New York: Oxford University Press.

Bjorklund, D. F., \& Pellegrini, A. D. (2000). Child development and evolutionary psychology. Child Development, 71(6), 1687-1708.

Bjorklund, D. F., \& Smith, P. K. (2003). Evolutionary developmental psychology: introduction to the special issue. Journal of Experimental Child Psychology, $85,195-198$.

Bussab, V. S. R., \& Ribeiro, F. L. (1998). Biologicamente cultural. In L. Souza M. F. Quintal Freitas \& M. M. P. Rodrigues (Orgs.), Psicologia: reflexões (im)pertinentes (pp.175-193). São Paulo: Casa do Psicólogo.

Charlesworth, W. R. (1992). Darwin and the development psychology past and present. Development Psychology, 28(1), 5-16.

Cole, M. (2002). Culture and development. In H. Keller, Y. H. Poortinga \& A. Schölmerich (Orgs.), Between culture and biology: perspectives on ontogenetic development (pp. 303-319). Cambridge: Cambridge University Press.

Geary, D. C., \& Bjorklund, D. F. (2000). Evolutionary Developmental Psychology. Child Development, 71(1), 57-65.

Geary, D. C. (2006). Evolutionary developmental psychology: current status and future directions. Developmental Review, 26, 113-119.

Gould, S. J. (1997). Três aspectos da evolução. In J. Brockman \& K. Matson (Orgs.), As coisas são assim: pequeno repertório científico do mundo que nos cerca (D. Meyer, S. S. Couto, Trad.) (pp. 95-100). São Paulo: Companhia das Letras. (publicado originalmente em 1995)

Greenfield, P. M., Keller, H.; Fuligni, A., \& Maynard, A. (2003). Cultural pathways through universal development. Annual Review of Psychology, 54, 461-490.

Grotuss, J., Bjorklund, D. F., \& Csinady, A. (2007). Evolutionary developmental psychology: developing human nature. Acta Psychologica Sinica, 39(3), 
439-453.

Kagitcibasi, C. (2005). Autonomy and relatedness in cultural context: implications for self and family. Journal of Cross-Cultural Psychology, 36(4), 403-422.

Kagitcibasi, C. (2007). Culture, self, and individualism-colletivism. In C. Kagitcibasi (Org.), Family, self, and human development across cultures: theory and applications (pp. 91-201). London: Lawrence Erlbaum Associates.

Keller, H. (2002). Development as the interface between biology and culture: a conceptualization of early ontogenetic experiences. In H. Keller, Y. H. Poortinga \& A. Schölmerich (Orgs.), Between culture and biology: perspectives on ontogenetic development (pp. 215-235). Cambridge: Cambridge Press.

Keller, H. (2007). Cultures of infancy. Mahwah: Lawrence Erlbaum Associates. Keller, H., Borke, J., Staufenbiel, T., Yovsi, R.D., Abels, M. Papaligoura, Z., ... $\mathrm{Su}$, Y. (2009). Distal and proximal parenting as alternative parenting strategies during infants' early months of life: a cross-cultural study. International Journal of Behavioral Development, 33(5), 412-420.

Keller, H., Borke, J., Yovsi, R., Lohaus, A., \& Jensen, H. (2005) Cultural orientationsand historical changes as predictors of parenting behaviour. International Journal of Behavioral Development, 29(3), 229-237.

Keller, H., \& Greenfield, P. M. (2000). History and future of development in crosscultural psychology. Journal of Cross-Cultural Psychology, 31(1), 52-62.

Mayr, E. (1988). Towards a new philosophy of biology. Cambridge: Belknap Press.

Miller, J. G. (1999). Cultural psychology: implications for basic psychological theory. Psychological Science, 10(2), 85-91.

Miller, J. G. (2002) Integrating cultural, psychological and biological perspectives in understanding child development. In H. Keller, Y. H. Poortinga \& A Schölmerich (Orgs.), Between culture and biology: perspectives on ontogenetic development (pp. 136-155). Cambridge: Cambridge Press University.

Ribas, A. F. P., \& Seidl-de-Moura, M. L. (2006). Abordagem sociocultural: algumas vertentes e autores. Psicologia em Estudo, 11(1), 129-138.

Ridley, M. (2004). O que nos faz humano: genes, natureza e experiência. (R. Vinagre, Trad.). Rio de Janeiro: Record. (Publicado originalmente em 2003)

Seidl-de-Moura, M. L. (2005). Bases para uma psicologia do desenvolvimento sociocultural e evolucionista. In F. A. R. Pontes, C. Magalhães, R. Brito \& W. Martin (Orgs.), Temas pertinentes à construção da psicologia contemporânea (pp. 16-41). Belém: EDUFPA.

Seidl-de-Moura, M. L., Lordelo, E., Vieira, M. L., Piccinnini, C. A., Siqueira, J. O. Magalhães, C. M. C. ... Rimoli, A. (2008). Brazilian mothers' socialization goals: intracultural differences in seven cities. International Journal of Behavioral Development, 32(6), 465-472.

Tooby, J., \& Cosmides, L. (1992). The psychological foundations of culture. In J. Tooby \& L. Cosmides (Orgs.), The adapted mind: evolutionary psychology and the generation of culture (pp. 19-127). New York: Oxford University Press.

Triandis, H. C.; Bontempo, R.; Villareal, M. J.; Asai, M., \& Lucca, N. (1988). Individualism and collectivism: cross-cultural perspectives on self-ingroup relationships. Journal of Personality and Social Psychology, 54(2), 323-338.

van de Vijver, F. J., \& Leung, K. (2000). Methodological issues in psychological research on culture. Journal of Cross-Cultural Psychology, 31(1), 33-51.

Vieira, M. L., Seidl-de-Moura, M. L., Lordelo, E., Piccinini, C., Martins, G. D. F., Macarini, S. M., ... Rimoli, A. O. (2010). Mother's beliefs about childrearing practices in seven Brazilian cities. Journal of Cross-Cultural Psychology, 41(2), 195-211.

1. Fenótipos são as características visíveis de um indivíduo, que são definidas pela expressão do seu genótipo (patrimônio hereditário), somada à influência exercida pelo ambiente.

Gabriela Dal Forno Martins, mestre em Psicologia pela Universidade Federal de Santa Catarina, é bolsista do CNPq como doutoranda do Programa de Pós-graduação em Psicologia da Universidade Federal do Rio Grande do Sul. Endereço para correspondência:

Rua Santana, 523, Farroupilha, Porto Alegre-RS. CEP: 90040-373. Telefone: (55) 3322-3911.

E-mail: gdalfornomartins@gmail.com

Mauro Luís Vieira, pós-doutor pela Dalhousie University, Canadá, é pesquisador 2 do CNPq e professor associado da Universidade Federal de Santa Catarina. E-mail: maurolvieira@gmail.com 